\title{
A Stackelberg Game Theoretic Analysis of Incentive Effects under Perceived Risk for China's Straw-Based Power Plant Supply Chain
}

\author{
Lingling Wang ${ }^{1}$ and Tsunemi Watanabe ${ }^{1,2, *}$ \\ 1 School of Economics and Management, Kochi University of Technology, 2-22 Eikokuji-cho, Kochi City, \\ Kochi 780-8515, Japan; wang.lingling@kochi-tech.ac.jp \\ 2 Graduate School of Engineering, Kochi University of Technology, Miyanokuchi 185, Tosayamada-cho, \\ Kami City, Kochi 782-0003, Japan \\ * Correspondence: watanabe.tsunemi@kochi-tech.ac.jp; Tel.: +81-088-821-7151
}

Academic Editor: Calliope Panoutsou

Received: 13 April 2016; Accepted: 6 June 2016; Published: 14 June 2016

\begin{abstract}
The rapid expansion of the biomass power generation industry has resulted in the conversion of substantial agricultural waste (crop straw) into energy feedstock, thereby increasing the income of farmers and promoting the development of rural areas. However, the promising industry faces financial deficits because of difficulties in collecting straw from farmers. To determine strategies for overcoming the biomass supply problem, we apply Stackelberg game theory in modeling the Chinese biomass supply chain and design incentive scenarios under stakeholder risk perception. We illustrate the proposed methodology through an empirical case study on China and demonstrate the effects of incentives on farmers and middlemen. Results show that with incentives, straw quantity and stakeholder profit are expected to increase. Incentives exert a particularly remarkable effect on farmers, with such inducements producing the highest social welfare. Moreover, perceived risk dramatically affects stakeholder profit. Mitigating the risk perception of farmers is expected to significantly advance the development of the biomass power generation industry, increase stakeholder profit, and decrease the amount of incentives needed.
\end{abstract}

Keywords: supply chain; biomass power plant; stackelberg game theory; perceived risk

\section{Introduction}

China is confronted with huge challenges in balancing energy demand and environmental improvement. Under rapid economic development, its energy consumption increased by $9.1 \%$ from 1992 to 2010; this rate is much faster than the world average of 2.6\% [1]. Energy consumption in the country continues to be dominated by coal, accounting for $66.0 \%$ of total consumption in 2013 [2]. Such consumption levels have increased the severity of air pollution in China, thereby drawing public attention toward renewable energy sources.

Crop straw is abundant in China, with annual production amounting to approximately 728 million tons; it is, therefore, one of the most frequently used sources of renewable energy [3]. Supply is expected to keep rising as agricultural production increases [1,4]. When agricultural residues are unconsumed, crop straw is burned in farmlands; such burning not only increases air pollution but also destroys farmland nutrition and wastes biomass energy. The use of crop straw for electricity generation has recently gained considerable support in China. Accordingly, straw-based biomass power generation in the country is rapidly developing. This form of alternative energy generation presents a number of advantages. The conversion of agricultural residues into biomass-based fuels is expected to reduce external costs to a level greater than that achieved with fossil fuels [5], as well as 
minimize agricultural burden and increase farm income [6]. The industrial processes involved in energy production also increase employment in regional areas, thereby expanding rural development [7]. Given the significance of using crop residues in rural China, the government included the production of bioenergy from crop residues in its Twelfth Five-Year Plan for national and social development.

Despite the intensity with which alternative energy measures are pursued in the country, however, the implementation of straw-based biomass generation has been an uphill battle for the government and developers. Almost 70\% of straw-based power plants struggled with financial deficits in 2012 even as straw-based electricity was purchased by the State Grid Corporation of China at a fixed price 1.5 times higher than that of conventional electricity [8]. This problem is attributed to the fact that raw material costs account for more than $55 \%$ of the total cost of straw-based power generation [9]. High costs do not originate from a shortage of crop residues but from lack of expertise in supply chain management. An important issue is that in China, crop residues are scattered across large areas, and collection is impossible without cooperation from farmers. Farmers are, therefore, key stakeholders in the supply of crop straw. Biomass power plants can receive incentives from the government, but the effects of economic incentives do not solve the shortage problem. An essential requirement, then, is to consider how stakeholder participation in the supply chain can be motivated and how the benefits that stakeholders receive can be optimized.

With these considerations in mind, we propose a Stackelberg game theoretic approach to modeling and analyzing the process of incentivizing farmers and middlemen under perceived risk. In the biomass supply chain, three actors are considered: biomass power plants, middlemen, and farmers. Game theoretic approaches have been widely used in the renewable energy field [10-13]. Nasiri and Zaccour were the first to apply the theory in investigating the challenges that confront the biomass generation industry [14]. On the basis of Nasiri's model, Wen and Zhang designed a straw acquisition mode for China's straw power generation system [10]. The reality is that actors implement decisions under perceived risk. To the best of our knowledge, no study has incorporated uncertainty and risk in game theoretic analyses of the biomass power generation industry. To fill this void, the present research (1) simulates the current situation (i.e., no government incentive scheme for farmers or middlemen; serving as a benchmark), incentivization for farmers, and incentivization for middlemen; (2) verifies the simulations with a case study and determines equilibrium under the three scenarios; and (3) identifies the optimal incentive strategy for China's biomass power generation sector.

The rest of the paper is organized as follows. Section 2 presents a review of the literature on biomass supply chains and the Stackelberg game theoretic approach. Sections 3 and 4 discuss the proposed Stackelberg game model through which we analyze the involvement of key stakeholders, straw-based power plants, middlemen, and farmers in the straw supply chain under perceived risk, and obtain the equilibrium of the model. Section 5 describes the model application to the case of the National Bioenergy Power Plant in China. Incentive effects under perceived risk are also determined and discussed. Section 6 presents conclusions and policy implications.

\section{Literature Review}

In recent years, game theory has been used to inform decision-making in marketing economics and supply chain management, among other fields. The solutions provided by the theory usually emerge from the interaction between the "players" involved in a game. Game theory has been extensively applied to solve problems of coordination among stakeholders in a supply chain. A number of studies have also discussed the theory from the perspectives of economic stability and supply chain efficiency [15-18]. With respect to the different power levels in a supply chain, the player that first makes a decision is generally regarded as dominating over other players in the chain. Stackelberg game theory is used to examine coordination among such types of players. For example, Choi [19] and Lee and Staelin [20] employed a Stackelberg game in which the retailer that first specifies the retail margin is identified to model a situation involving a power retailer. A Stackelberg game can be used to identify the best way for a manufacturer to coordinate a channel in the presence of a power retailer [21]. 
Leng and Parlar investigated a multiple-supplier and single-manufacturer supply chain to discuss the Nash and Stackelberg equilibria and coordinate the chain with the use of cost-sharing contracts [16]. Although game theory has been extensively used in various disciplines, its application in bioenergy is still in its infancy. Benjamin and Houee-Bigot studied crop markets and simulated the effects of alternative national and international policies by using a partial equilibrium model [22]. Nasiri and Zaccour, who employed a Stackelberg game to analyze a biomass electricity generation supply chain, used the Canadian context as the basis in proposing that a sequential game unfolds among electric utility companies, electricity generators, and farmers [14]. Using game theory, Sun et al. probed into the interaction mechanism of cost risks for biomass material supply in power generation [23]. On the basis of a Chinese case study, the authors determined the benefits derived from price alliance. As previously stated, Wen and Zhang used Stackelberg game theory to design a straw acquisition model for a straw-based power plant in China [10].

Cognitive psychology maintains that perception, motivation, and attitude play an important role in decision-making [24,25]. Risk perception among stakeholders is also a principal factor for modulating activity during decision-making processes [26]. Perceived risk arises when a stakeholder is involved in situations wherein consequences are uncertain $[27,28]$. Perceived risk theory enables marketers to understand the world from a consumer's perspective, and risk perception analysis is useful in informing resource allocation decisions in the market [29]. Perceptions regarding risk exert an equally important effect on the decision-making process of actors involved in biomass supply chains.

Notwithstanding the recognition of the importance of risk perception and the insights provided by the studies discussed above, few researchers have incorporated the risk perceived by players into game theoretic analyses to validate incentive effects on biomass supply chains.

\section{Model}

\subsection{Background}

Unlike the agricultural ownership systems in the US and European countries, farmland ownership in China is regarded as a household responsibility. Crop holders are thousands of small farming households that own small farming areas scattered across different regions [30]. After crops are harvested, farmers use straw for house heating and livestock feeding, but most bales of straw are left unconsumed on farmland. The increasing standard of living in rural China has motivated a preference for gas over straw as house heating fuel. Under this backdrop, more crop straws become agricultural waste. To convert crop straw into feedstock for biomass power plants, farmers employ two methods: (a) they transport straw from farmlands and pile straw bales near roads, after which middlemen convey the straw to collection stations for processing before the supply is sent to biomass power plants; alternatively, (b) farmers who live near a biomass power plant can borrow a machine for processing crop straw and send the processed product to the plant. Mode $(b)$ is rarely used because few farmlands are located near biomass power plants. This study, therefore, focuses on Mode (a). The entire process that characterizes Mode (a) entails tremendous manpower, thus making middlemen necessary participants in the process. These individuals serve as the connection between biomass power plants and farmers. Middlemen purchase crop straw from farmers at a certain price and transport the raw materials to collection stations. After being processed, the materials are stored and sold to power plants when needed.

As can be seen, farmers, middlemen, and biomass power plants play different, but critical, roles in the biomass supply chain in China. In reality, however, the collection of crop straw does not proceed as smoothly as one might expect because it is influenced by the risk perceptions held by each of the stakeholders. The most crucial perceived risk among biomass power plants is bankruptcy, given the high cost of feedstock. Among middlemen, building trust with farmers and reducing the purchase price significantly guarantee the benefits that they derive from their occupation. Investigations (such as that conducted in 2014 by the authors) of biomass supply indicate that farmers' risk perceptions (e.g., low 
trust in middlemen, costs outweighing benefits, marginal profits) raise crop straw prices to exorbitant levels, thereby increasing the cost of feedstock used by biomass power plants. In particular, the risk perceptions held by farmers and middlemen diminish their motivation to supply straw. Currently, incentives are available only to biomass power plants-a strategy that is ineffective in increasing straw collection given that it does not establish a connection between local governments and farmers. Without encouragement from local governments, increasing farmers' awareness of the significance of supplying straw is difficult. More importantly, without economic compensation, most farmers are discouraged from providing straw to middlemen. Ensuring the development of the biomass power generation industry necessitates the design of appropriate incentive mechanisms. Correspondingly, this study discusses appropriate incentive structures for farmers, middlemen, and biomass power plants (Figure 1) [31].

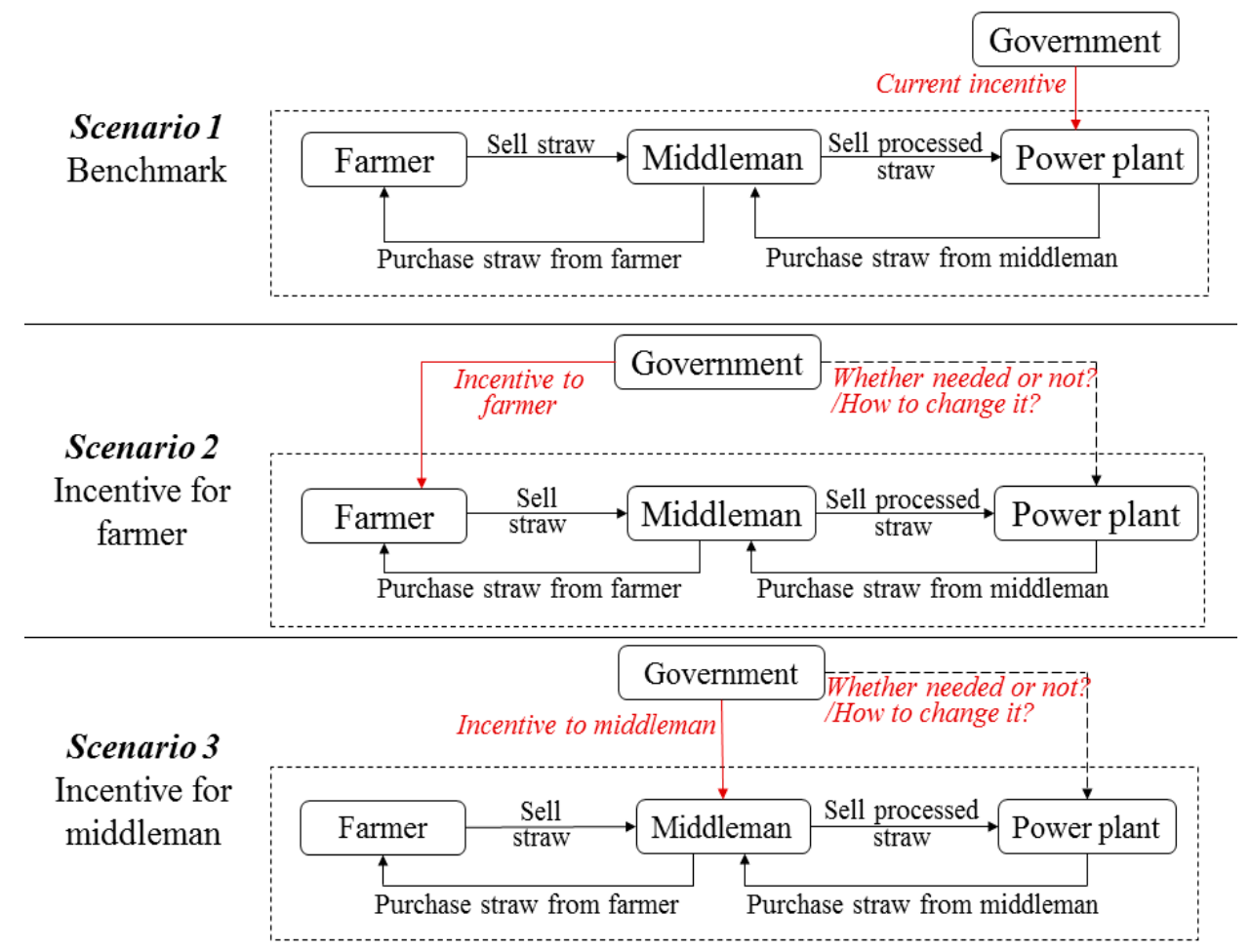

Figure 1. Biomass supply chain under different incentive scenarios.

\subsection{Stackelberg Game Model}

\subsubsection{Assumptions}

In the proposed Stackelberg game model, three players are considered: a biomass power plant (player B), which is an electricity generator and crop straw consumer; a middleman (player M), who acts as an intermediary between the biomass power plant and farmers; and a farmer (player F), who supplies crop straw and decides on supply quantity. Each stage in this setting is simplified by assuming the involvement of one player, but this setting is unrealistic from the perspectives of economies of scale and stability [14]. Before model development, therefore, certain assumptions should be formulated to transform modeling results into reliable decision suggestions [32]. In this research, these assumptions are as follows:

1. Biomass types and planting conditions do not cause significant differences in biomass quantity, collection, and storage.

2. Straw production and collection are carried out in one year. Seasonal factors and transport and processing losses are disregarded for convenience in calculation. 
3. In the straw collection process, a biomass power plant is usually in the central position [33]. The collection area is envisioned as a circular region to minimize transportation costs. The average distance from the collection station to the biomass power plant is L kilometers. $\mathrm{L}$ is treated as a known variable, $30 \mathrm{~km}$, which is estimated by the biomass power plant. (Figure 2) [31].

4. We assume that the farmer transports crop straw to a collection station. As previously stated, the collection area is conceived of as a circular island to minimize transportation costs. The maximum radius of the area for straw collection is denoted by Rmax (m), and the radius spanned by straw collection is represented by $R i(\mathrm{~m})$. Tortuosity factor $\beta$ is introduced to adjust transport distance, which is not a straight line. If the ratio of the quantity of used crop straw to biomass feedstock output is $\mathrm{k}(k \in[0,1])$, then the cost of crop straw collection is:

$$
\begin{aligned}
C_{q}\left(q_{2}\right) & =\int_{0}^{R_{i}} 2 \pi r \cdot \alpha_{i} \cdot \beta \cdot k \cdot r \cdot p_{t} \cdot d r \\
& =\frac{2}{3} q_{2} 2^{\frac{3}{2}} \cdot \beta \cdot\left(\pi \cdot \alpha_{i} \cdot k\right)^{-\frac{1}{2}} p_{t}
\end{aligned}
$$

where $q_{2}$ is the quantity of crop straw supplied by the farmer (ton), $\alpha_{i}$ is the crop straw output in a unit area $\left(\mathrm{t} / \mathrm{m}^{2}\right)$, and $P_{t}$ is the unit cost of biomass transportation (US\$/t). Given that most farmers usually harvest straw by themselves, labor cost is disregarded.

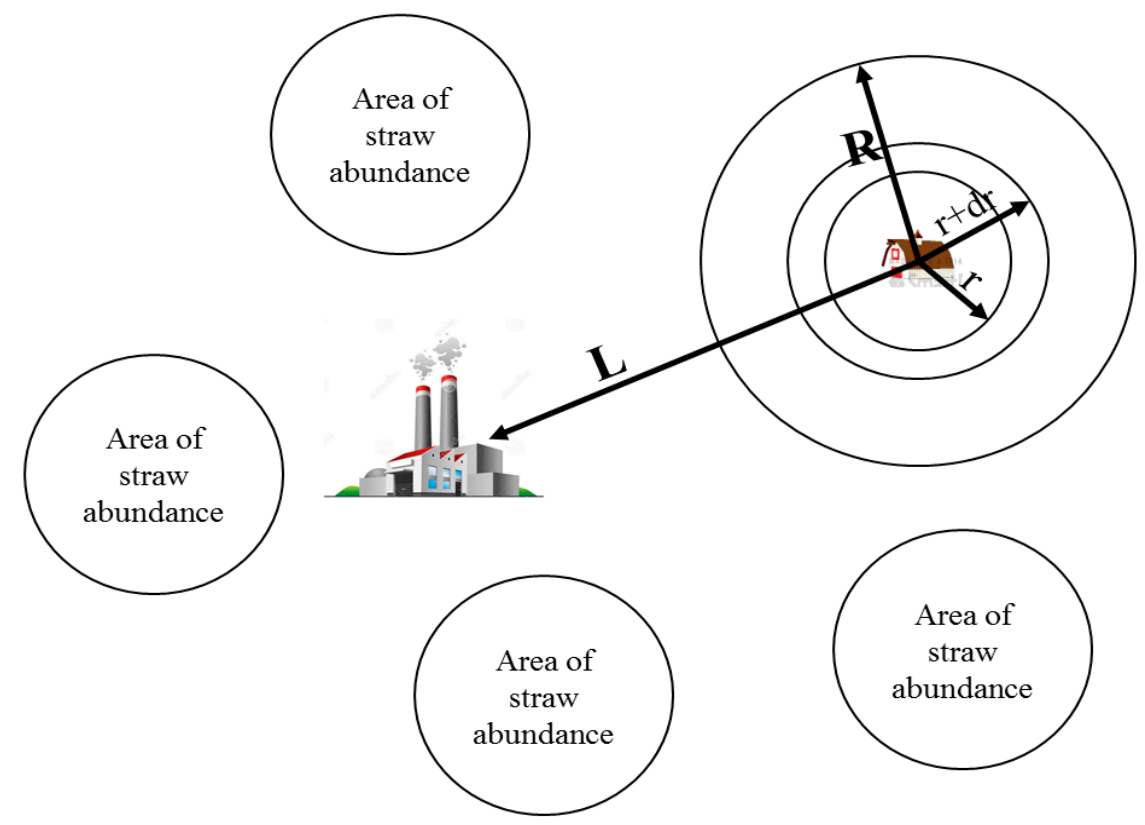

Figure 2. Assumptions regarding collection area, transportation distance, and straw supply quantity.

If

$$
C_{q}=\beta \cdot\left(\pi \cdot \alpha_{i} \cdot k\right)^{-\frac{1}{2}} p_{t}
$$

Then

$$
C_{q}\left(q_{2}\right)=\frac{2}{3} q_{2}^{\frac{3}{2}} \cdot C_{q}
$$

5. In line with Chinese policy, all electricity generated from biomass has been purchased by the State Grid Corporation of China at a price Pe since 2010 [9]. Pe, including the incentive that the government provides to biomass power plants, is higher than the price of electricity generated from fossil fuels.

6. Given limitations in the installed capacity of biomass power plants, a maximal annual quantity of straw demand exists $\left(q_{1}\right)$. This study assumes that the total amount of straw for biomass power plant is $q_{1}$. 
7. We assume that thousands of farmers supply crops and more than 100 middlemen serve the biomass power plant. Although these individuals engage in various behaviors, the farmer and middleman groups share commonalities. Farmers and middlemen are, therefore, assumed as two entities denoted as player group $\mathrm{F}$ and player group $\mathrm{M}$, respectively.

8. In the biomass supply chain, all of the stakeholders (i.e., biomass power plant, middleman, and farmer) perceive some risk. To accurately model the straw supply situation, the risk perception of each player is considered in the game model as the risk coefficient. This study assumes that the risk coefficients of the biomass power plant $\left(R_{B}\right)$, middleman $\left(R_{M}\right)$, and farmer $\left(R_{F}\right)$ are distributed in $(0,0.1)$ and that $R_{B}=R_{M}=R_{F}$.

9. We assume that no bargaining process exists. Due to of the unequal positions among the biomass power plant, middleman, and farmer, the leading position is occupied by the biomass power plant, followed by the farmer.

10. This study did not consider competition with other biomass power plants in the collection radius of $30 \mathrm{~km}$. The optimal radius in collecting straw is $30 \mathrm{~km}$ for one biomass power plant estimated by biomass power plants, investors, and local government. Additionally, it is illegal to construct more than one biomass power plant regulated by local government in order to prevent vicious competition for straw.

\subsubsection{Stackelberg Game Decision Model}

In the Stackelberg game decision model, the biomass power plant makes the first move and reveals its purchase price to the middleman. Knowing this information, the middleman announces its purchasing rule and price to the farmer. On the basis of the purchasing rule and price, the farmer decides on the quantity of crop straw $\left(q_{1}\right)$ that he is willing to sell to the middleman. Given that this study centers on the interaction among the aforementioned stakeholders, the game is played sequentially (Figure 3). All of the decision-makers seek to maximize their own profit. As shown in Figure 3, the decision problems of the three profit-maximizing players are identified as $\alpha_{a}, p_{f}$, and $q_{1}$, which denote the decision variables of the biomass power plant (coefficient of incentive for middleman), middleman (price of purchase from farmer), and farmer (quantity of crop straw provided), respectively.

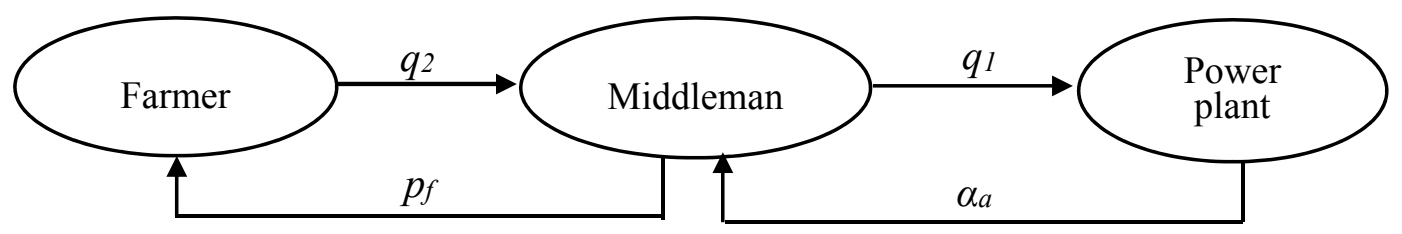

Figure 3. Decision variables in biomass supply chain.

1. Scenario 1: Benchmark incentive situation

Biomass power plant: Considering the risks that the biomass power plant may face, the maximization of its profit is defined as follows:

$$
\begin{aligned}
\max _{\alpha_{a} \geqslant 0} \prod_{B} & =\left\{\left(p_{e}-O C\right) r q_{1}-p_{a} q_{1}-C_{1} q_{1}-R_{B}\left(p_{a} q_{1}+C_{1} q_{1}\right)\right\} \\
& =\left\{\left(p_{e}-O C\right) r q_{1}-\left(1+R_{B}\right)\left(p_{a} q_{1}+C_{1} q_{1}\right)\right\}
\end{aligned}
$$

subject to:

$$
p_{a}=p_{m}\left(1+\alpha_{a}\right)
$$

where $O C$ is the biomass power plant's operation cost per unit for generated electricity (US\$/MWh), $r$ is the ratio of conversion from biomass to electricity ( $\mathrm{MWh} / \mathrm{ton}$ ), $p_{a}$ denotes the price that the biomass power plant offers to the middleman, $p_{m}$ is the market price of processed biomass, and $C_{1}$ represents the storage cost borne by the biomass power plant. 
Here, $R_{B}$ refers to the biomass power plant's risk coefficient, which is the rate of cost increase associated with the risk perceived by the plant manager. If the manager has a risk-neutral attitude, this value is the rate of expected cost increase. If the manager holds a risk-averse attitude, this value is higher than the rate of expected cost increase. This coefficient can, thus, be interpreted as the certainty equivalent.

The model clearly determines the biomass power plant's decision-making on the amount of incentive to be provided to the middleman. The amount of biomass that the biomass power plant receives from the middleman $\left(q_{1}\right)$ depends on the incentive, which is associated with the generated electricity $\left(r q_{1}\right)$. The market price of biomass production $\left(p_{m}\right)$ reflects the most reasonable price estimated by the biomass power plant in accordance with the current situation.

Middleman: The profit maximization problem of the middleman is given by:

$$
\begin{aligned}
\max _{p_{a}>P_{f} \geqslant 0} \Pi_{M} & =\left\{p_{a} q_{1}-p_{f} q_{2}-\left(\mathrm{C}_{t} \mathrm{~L}+C_{2}\right) q_{2}-R_{M}\left(p_{f} q_{2}+\left(\mathrm{C}_{t} \mathrm{~L}+C_{2}\right) q_{2}\right)\right\} \\
& =\left\{p_{a} q_{1}-\left(1+R_{M}\right)\left(p_{f} q_{2}+\left(\mathrm{C}_{t} \mathrm{~L}+C_{2}\right) q_{2}\right)\right\}
\end{aligned}
$$

subject to:

$$
\begin{gathered}
q_{1}=0.75 \times q_{2} \\
p_{a}=p_{m}\left(1+\alpha_{a}\right)
\end{gathered}
$$

where $p_{f}$ denotes the crop straw purchase price charged by the farmer (US $\$ /$ ton), $C_{t}$ represents the transportation cost (US\$ $/ \mathrm{km} \cdot$ ton), $C_{2}$ is the cost of storage in the collection station (US $\$ / \mathrm{ton}$ ), L denotes the average transportation distance from the collection station to the biomass power plant $(\mathrm{km})$, and $q_{2}$ is the weight of the straw collected from the farmer. The bales of crop straw contain more moisture after they are purchased from the farmer than after purchase by the biomass power plant from the middleman. Thus, $q_{2}$ and $q_{1}$ are unequal in weight. $R_{M}$ is the risk coefficient of the middleman.

Farmer: On the basis of the price charged by the middleman, the farmer decides on the quantity of biomass that he wants to provide. Taking into account cost function (1), which comprises desirable properties, the farmer's profit maximization problem is expressed thusly:

$$
\begin{aligned}
\max _{q \geqslant 0} \prod_{F} & =\left\{p_{f} q_{2}-C_{q}\left(q_{2}\right)-\mathrm{R}_{F} C_{q}\left(q_{2}\right)\right\} \\
& =\left\{p_{f} q_{2}-\left(1+\mathrm{R}_{F}\right) C_{q}\left(q_{2}\right)\right\}
\end{aligned}
$$

subject to:

$$
C_{q}(\mathrm{q})=\frac{2}{3} C_{q} q_{2}^{\frac{3}{2}}
$$

where $p_{f} \times q_{2}$ stands for the farmer's income from selling crop straw to the middleman, and $\left(1+R_{F}\right) C_{q}\left(q_{2}\right)$ represents the cost of self-collection and transportation under the farmer's risk perception.

\section{Scenario 2: Incentive for the farmer}

Farmer: After the provision of the government incentive, the profit maximization problem of the farmer is given by:

$$
\begin{aligned}
\max _{q \geqslant 0} \prod_{F} & =\left\{p_{f} q_{2}+\alpha_{g f} p_{m} q_{2}-\left(1+\mathrm{R}_{F}\right) C_{q}\left(q_{2}\right)\right\} \\
& =\left\{p_{f} q_{2}+\alpha_{g f} p_{m} q_{2}-\frac{2}{3} C_{q} q_{2}^{\frac{3}{2}}\left(1+\mathrm{R}_{F}\right)\right\}
\end{aligned}
$$

subject to:

$$
C_{q}(q)=\frac{2}{3} C_{q} q_{2}^{\frac{3}{2}}
$$

where $\alpha_{g f}$ represents the incentive from the government. 
3. Scenario 3: Incentive for the middleman

Middleman: After the provision of the government incentive, the profit maximization problem of the middleman is:

$$
\max _{p_{a}>p_{f} \geqslant 0} \prod_{M}=\left\{p_{a} q_{1}+\alpha_{g m} p_{m} q_{1}-\left(1+R_{M}\right)\left(p_{f} q_{2}+\left(\mathrm{C}_{t} \mathrm{~L}+\mathrm{C}_{2}\right) q_{2}\right)\right\}
$$

subject to:

$$
\begin{gathered}
q_{1}=0.75 \\
p_{a}=p_{m}\left(1+\alpha_{a}\right)
\end{gathered}
$$

where $\alpha_{g m}$ denotes the incentive from the government.

\section{Equilibrium}

As stated earlier, the Stackelberg game is played sequentially. The leading position is occupied by the biomass power plant, followed by the middleman, and then the farmer. The leading player can anticipate the response of the followers to its strategic choice. With backward induction, the equilibrium solution begins from the farmer's decision problem.

\subsection{Determination of Equilibrium in the Benchmark Scenario (Scenario 1)}

Proposition 1 . Let $\partial \prod_{F} / \partial q_{1}=0$. The farmer's optimal strategy for supplying biomass to the plant is calculated by:

$$
q_{1}^{*}=\left\{\begin{array}{c}
\frac{3}{4}\left(\frac{p_{f}}{\left(1+R_{F}\right) C_{q}}\right)^{2} p_{f}>0 \\
0 \quad p_{f}=0
\end{array}\right.
$$

subject to:

$$
C_{q}(q)=\frac{2}{3} C_{q} q_{2}^{\frac{3}{2}}
$$

The decision regarding the farmer's supply strategy is positively affected by the middleman's purchase price $\left(p_{f}\right)$; that is, a decrease in $p_{f}$ motivates an increase in supply.

Proposition 2. Substituting $q_{1}$ from Equation (7) into Equation (3), let $\partial \prod_{M} / \partial p_{f}=0$. The middleman's purchase price strategy $\left(p_{f}^{*}\right)$ under risk perception is given by:

$$
p_{f}^{*}=\frac{3 p_{m}\left(1+\alpha_{a}\right)-4\left(C_{t} L+C_{2}\right)\left(1+R_{M}\right)}{6\left(1+R_{M}\right)} \alpha_{a}>\frac{4\left(C_{t} L+C_{2}\right)\left(1+R_{M}\right)}{3 p_{m}}
$$

otherwise:

$$
p_{f}^{*}=0
$$

Proposition 2 states that the purchase price from $p_{f}$ will increase if the middleman obtains a better offer from the biomass power plant. If the middleman's risk perceptions decrease $\left(R_{M}\right)$, then it can also offer a better purchase price to the farmer. This result underscores the fact that without an increase in the middleman's purchase price, decreasing its risk significantly increases the purchase price charged by the farmer.

Proposition 3. On the basis of Equation (2), we substitute $q$ from Equation (7) and $p_{f}$ from Equation (8) into Equation (2). Let $\partial \prod_{B} / \partial \alpha_{a}=0$. The biomass power plant's pricing incentive strategy $\alpha_{a}$ is given by:

$$
\alpha_{a}^{*}=\frac{6 r\left(p_{e}-O C\right)}{9 p_{m}\left(1+R_{B}\right)}-\frac{4\left(C_{t} L+C_{2}\right)\left(1+R_{M}\right)-6 C_{1}}{9 p_{m}\left(1+R_{B}\right)}-1 \quad p_{e}>\frac{\left(1+R_{B}\right)\left[9 p_{m}+6 C_{1}-4\left(C_{t} L+C_{2}\right)\left(1+R_{M}\right)\right]}{6 r}+O C
$$

Proposition 3 indicates that under a fixed electricity price from the State Grid Corporation of China and fixed costs (e.g., operations, storage, and transportation costs), the biomass power plant 
will decrease the incentive $\left(\alpha_{a}\right)$ that it provides to the middleman if the biomass power plant's risk coefficient $\left(R_{B}\right)$ increases. Meanwhile, the biomass power plant is compelled to increase the purchase price that it charges the middleman in cases where in the middleman holds a high risk perception.

Triplet $E^{*}=\left(\alpha_{a}^{*}, p_{f}^{*}, q_{1}^{*}\right)^{T}$ from Equations (7) to (9) is the Nash equilibrium of the Stackelberg game in the benchmark scenario (Scenario 1). Incorporating the biomass power plant's equilibrium incentive for the middleman $\left(\alpha_{a}{ }^{*}\right)$ and the purchase price that the middleman offers to the farmer into Equations (8) and (7), respectively, we obtain:

$$
E^{*}=\left(\begin{array}{c}
\frac{6 r\left(p_{e}-O C\right) \frac{1}{\left(1+R_{B}\right)}+4\left(C_{t} L+C_{2}\right)\left(1+R_{M}\right)-6 C_{1}}{9 p_{m}}-1 \\
\frac{3\left(p_{e}-O C\right) r-4\left(1+R_{M}\right)\left(1+R_{B}\right)\left(C_{t} L+C_{2}\right)-3 C_{1}\left(1+R_{B}\right)}{9\left(1+R_{B}\right)\left(1+R_{M}\right)} \\
\frac{3}{4}\left[\frac{3\left(p_{e}-O C\right) r-4\left(1+R_{M}\right)\left(1+R_{B}\right)\left(C_{t} L+C_{2}\right)-3 C_{1}\left(1+R_{B}\right)}{9\left(1+R_{B}\right)\left(1+R_{M}\right)\left(1+R_{F}\right) C_{q}}\right]^{2}
\end{array}\right)
$$

\subsection{Determination of Equilibrium in the Farmer Incentive Scenario (Scenario 2)}

Proposition 4 . The farmer's optimal strategy for supplying biomass for biomass generation $\left(q_{1}{ }^{* *}\right)$ under incentivization from the government is given by:

$$
q_{1}^{* *}= \begin{cases}\frac{3}{4}\left(\frac{p_{f}+\alpha_{g f} p_{m}}{C_{q}\left(1+\mathrm{R}_{F}\right)}\right)^{2} & p_{f}>0 \\ 0 & p_{f}=0\end{cases}
$$

The quantity of biomass from the farmer increases with increasing incentive $\alpha_{g f}$ for the farmer.

Proposition 5. With the farmer's crop straw supply strategy, the middleman's purchase price strategy $p_{f}^{* *}$ under risk and uncertainty is:

$$
p_{f}^{* *}=\frac{3 p_{m}\left(1+\alpha_{a}\right)-4\left(1+R_{M}\right)\left(C_{t} L+C_{2}\right)-2\left(1+R_{M}\right) \alpha_{g f} p_{m}}{6\left(1+R_{M}\right)}, \quad \alpha_{a}>\frac{4\left(1+R_{M}\right)\left(C_{t} L+C_{2}\right)+2\left(1+R_{M}\right) \alpha_{g f} p_{m}}{3 p_{m}}-1
$$

otherwise:

$$
p_{f}^{* *}=0
$$

The provision of a government incentive to the farmer also influences the middleman's purchase price. Specifically, the government's incentive for the farmer reduces the middleman's purchase price $p_{f}^{* *}$.

Proposition 6. Given the pricing strategy offered by the middleman to the farmer, the biomass power plant's pricing incentive strategy $\alpha_{a}{ }^{* *}$ is given by:

$$
\begin{aligned}
\alpha_{a}^{* *} & =\frac{6 r\left(p_{e}-O C\right)}{9 p_{m}\left(1+R_{B}\right)}+\frac{4\left(1+R_{M}\right)\left(C_{t} L+C_{2}\right)-4\left(1+R_{M}\right) \alpha_{g f} p_{m}}{9 p_{m}}-\frac{6 C_{1}}{9 p_{m}}-1 \\
& p_{e}>\frac{9 p_{m}\left(1+R_{B}\right)-4\left(1+R_{M}\right)\left(1+R_{B}\right)\left(C_{t} L+C_{2}\right)+4\left(1+R_{M}\right)\left(1+R_{B}\right) \alpha_{g f} p_{m}+6\left(1+R_{B}\right) C_{1}}{6 r}+O C
\end{aligned}
$$

As indicated in Proposition 6, the incentive that the biomass power plant provides to the middleman $\left(\alpha_{a}^{* *}\right)$ is affected by the risk perceptions of both the biomass power plant and the middleman Additionally, an increase in $\alpha_{g f}$ results in a decrease in $\alpha_{a}^{* *}$.

Triplet $E^{* *}=\left(\alpha_{a}^{* *}, p_{f}^{* *}, q_{1}^{* *}\right)^{T}$ from Equations (10) to (12) is the Nash equilibrium of the Stackelberg game in the incentive scenario involving the farmer. Incorporating Equation (13) and (12) into Equations (12) and (11), respectively, yields.

$$
E_{1}^{* *}=\left(\begin{array}{c}
\alpha_{a}^{* *} \\
p_{f}^{* *} \\
q^{* *}
\end{array}\right)=\left(\begin{array}{c}
\frac{6 r\left(p_{e}-O C\right)+4\left(1+R_{M}\right)\left(1+R_{B}\right)\left(C_{t} L+C_{2}\right)-4\left(1+R_{M}\right)\left(1+R_{B}\right) \alpha_{g f} p_{m}-6 C_{1}\left(1+R_{B}\right)}{9 p_{m}\left(1+R_{B}\right)}-1 \\
\frac{3 r\left(p_{e}-O C\right)-4\left(1+R_{M}\right)\left(1+R_{B}\right)\left(C_{t} L+C_{2}\right)-5\left(1+R_{M}\right)\left(1+R_{B}\right) \alpha_{g f} p_{m}-3 C_{1}\left(1+R_{B}\right)}{9\left(1+R_{M}\right)\left(1+R_{B}\right)} \\
\frac{3}{4}\left(\frac{3 r\left(p_{e}-O C\right)-4\left(1+R_{B}\right)\left(1+R_{M}\right)\left(C_{t} L+C_{2}\right)+4\left(1+R_{B}\right)\left(1+R_{M}\right) \alpha_{g f} p_{m}-3 C_{1}\left(1+R_{B}\right)}{9 C_{q}\left(1+R_{B}\right)\left(1+R_{M}\right)\left(1+R_{F}\right)}\right)^{2}
\end{array}\right)
$$




\subsection{Determination of Equilibrium in the Middleman Incentive Scenario (Scenario 3)}

Proposition 7. The farmer's optimal strategy for supplying biomass for electricity is the same as Equation (7) under government incentivization for the middleman.

$$
q_{1}^{*}=\left\{\begin{array}{c}
\frac{3}{4}\left(\frac{p_{f}}{\left(1+R_{F}\right) C_{q}}\right)^{2} p_{f}>0 \\
0 \quad p_{f}=0
\end{array}\right.
$$

Proposition 8. Given the farmer's supply strategy, the middleman's pricing strategy $p_{f}^{* * *}$ is given by:

$$
p_{f}^{* * *}=\frac{3 p_{m}\left(1+\alpha_{a}\right)+3 \alpha_{g m} p_{m}-4\left(1+R_{M}\right)\left(C_{t} L+C_{2}\right)}{6\left(1+R_{M}\right)}, \quad \alpha_{a}>\frac{4\left(1+R_{M}\right)\left(C_{t} L+C_{2}\right)-3 \alpha_{g m} p_{m}}{3 p_{m}}-1
$$

otherwise:

$$
p_{f}^{* * *}=0
$$

As expected, after the provision of the government incentive to the middleman, purchasing more crop straw necessitates that the middleman increase the purchase price offered to the farmer (i.e., $\left.p_{f}^{* * *}\right)$. The rate of increase depends on the extent of government incentive that is provided to the middleman.

Proposition 9. Given the middleman's pricing strategy for his transaction with the farmer, the biomass power plant's pricing incentive strategy $\alpha_{a}^{* * *}$ is expressed as:

$$
\begin{gathered}
\alpha_{a}^{* * *}=\frac{6 r\left(p_{e}-O C\right)}{9 p_{m}\left(1+R_{B}\right)}-\frac{4\left(1+R_{M}\right)\left(C_{t} L+C_{2}\right)-6 C_{1}\left(1+R_{B}\right)}{9 p_{m}\left(1+R_{B}\right)}-\frac{3 \alpha_{g m}}{9 p_{m}}-1, \\
p_{e}>\frac{9 p_{m}\left(1+R_{B}\right)-4\left(1+R_{M}\right)\left(1+R_{B}\right)\left(C_{t} L+C_{2}\right)+6 C_{1}\left(1+R_{B}\right)+3 \alpha_{g m} p_{m}\left(1+R_{B}\right)}{6 r}+O C
\end{gathered}
$$

With the government's incentive for the middleman, the incentive that the biomass power plant provides to the middleman decreases.

Triplet $E^{* * *}=\left(\alpha_{a}^{* * *}, p_{f}^{* * *}, q_{1}^{* * *}\right)^{T}$ from Equations (13)-(15) is the Nash equilibrium of the Stackelberg game in the incentive scenario involving the middleman. Incorporating Equations (17) and (16) into Equations (16) and (15) yields the following Nash equilibrium $E^{* * *}$ :

$$
E^{* * *}=\left(\begin{array}{c}
\alpha_{a}^{* * *} \\
p_{f}^{* * *} \\
q^{* * *}
\end{array}\right)=\left(\begin{array}{c}
\frac{6 r\left(p_{e}-O C\right)+4\left(1+R_{M}\right)\left(1+R_{B}\right)\left(C_{t} L+C_{2}\right)-6 C_{1}\left(1+R_{B}\right)-3 \alpha_{g a} p_{m}\left(1+R_{B}\right)}{9 p_{m}\left(1+R_{B}\right)}-1 \\
\frac{3 r\left(p_{e}-O C\right)-4\left(1+R_{M}\right)\left(1+R_{B}\right)\left(C_{t} L+C_{2}\right)-3 C_{1}\left(1+R_{B}\right)+3\left(1+R_{B}\right) \alpha_{g a} p_{m}}{9\left(1+R_{M}\right)\left(1+R_{B}\right)} \\
\frac{3}{4}\left(\frac{3 r\left(p_{e}-O C\right)-4\left(1+R_{M}\right)\left(1+R_{B}\right)\left(C_{t} L+C_{2}\right)-3 C_{1}\left(1+R_{B}\right)+3\left(1+R_{B}\right) \alpha_{g a} p_{m}}{9 C_{q}\left(1+R_{B}\right)\left(1+R_{M}\right)\left(1+R_{F}\right)}\right)^{2}
\end{array}\right)
$$

\section{Case Study}

\subsection{Case Introduction}

Heilongiiang Province is an important grain crops base in China and is expected to serve as a base of biomass supply for electricity generation. We, therefore, conducted an empirical study on the national bioenergy industry of Wangkui County in Heilongjing Province. The total investment of the investigated biomass power plant is US $\$ 2.3$ million, and its installed capacity is $30 \mathrm{MW}$. The annual demand for processed crop straw is 200,000 tons. With the help of the company managers and local government, the investigation was conducted. After obtaining data, we assigned values to the parameters (Table 1). We ran a set of experiments on the problems arising under the incentive schemes that correspond to the three scenarios:

1. Scenario 1: No government incentive for farmers or middlemen (current situation)

2. Scenario 2: Government incentive for farmers, with each stakeholder's profit maximized

3. Scenario 3: Government incentive for middlemen, with each stakeholder's profit maximized 
Table 1. Parameter values from field survey.

\begin{tabular}{cccc}
\hline Parameter & Value & Parameter & Value \\
\hline$P_{m}$ & US $\$ 40 /$ ton & $r$ & $860 \mathrm{MWh} / \mathrm{ton}$ \\
$C_{1}$ & US $\$ 5 /$ ton & $L$ & $30 \mathrm{~km}$ \\
$C_{2}$ & US $\$ 6 /$ ton & OC & US $\$ 0.05 / \mathrm{MWh}$ \\
$C_{t}$ & US $\$ 0.8 / \mathrm{km} \cdot$ ton & $C_{q}$ & $\mathrm{US} \$ 1 / \mathrm{m}^{2}$ \\
\hline
\end{tabular}

Source: Investigation in 2014.

\subsection{Results and Discussion}

\subsubsection{Scenario 1: Current Incentive Scenario}

Substituting the parameter values into the model allows us to determine the Nash equilibrium under the current incentive situation:

$$
E^{*}=\left(\alpha_{a}^{*}, p_{f}^{*}, q_{1}^{*}\right)^{T}=\left(\begin{array}{c}
\frac{43\left(p_{e}-0.05\right)}{3(1+R)}+\frac{(1+R)}{3}-\frac{13}{12} \\
\frac{860\left(p_{e}-0.05\right)}{3(1+R)^{2}}-\frac{5}{3(1+R)}-\frac{40}{3} \\
\frac{1}{12}\left[\frac{860 \times\left(p_{e}-0.05\right)}{(1+R)^{3}}-\frac{5}{(1+R)^{2}}-\frac{40}{(1+R)}\right]^{2}
\end{array}\right)
$$

Results are derived on the basis of the effects of each stakeholder's risk perception on $\alpha_{a}, p_{f}$, and $q_{1}$ in the current incentive situation. The findings with respect to changes in risk coefficient (from 0 to 0.1 ) are presented in Figure $4 \mathrm{a}-\mathrm{f}$. Incorporating $\alpha_{a}, p_{f}$, and $q_{1}$ into the profit models of the biomass power plant, middleman, and farmer. The profits of the three players are represented by the following formulae and yields a plot of profit change under changes in perceived risk (Figure $4 \mathrm{a}-\mathrm{c}$ ).

$$
\begin{aligned}
\prod_{B} & =\frac{1}{36(1+R)^{6}}\left[860\left(p_{e}-0.05\right)-40(1+R)^{2}-5(1+R)\right]^{3} \\
\prod_{M} & =\frac{1}{54(1+R)^{7}}\left[860\left(p_{e}-0.05\right)-40(1+R)^{2}-5(1+R)\right]^{3} \\
\prod_{F} & =\frac{1}{81(1+R)^{8}}\left[860\left(p_{e}-0.05\right)-40(1+R)^{2}-5(1+R)\right]^{3}
\end{aligned}
$$

Let us consider the effects of risk on the biomass power plant's incentive for the middleman $\left(\alpha_{a}\right)$, the straw purchase price that the farmer offers to the middleman $\left(p_{f}\right)$, the farmer's supply quantity $\left(q_{1}\right)$, and the biomass power plant's profit change $\left(\pi_{B}\right)$. In the current incentive situation, the dominant direction of the lines in Figure 4 reflect a considerably strong effect of perceived risk on $\alpha_{a}, p_{f}, q_{1}, \pi_{B}$, $\pi_{M}$, and $\pi_{F}$. In particular, the profit of the biomass power plant remarkably decreases with increasing perceived risk.

The field survey that we carried out indicates that a rising $p_{f}$ results in an increased quantity of straw supply. To obtain sufficient straw for normal operations, the biomass power plant or the middleman should collect straw from distant locations, which are beyond the assumed island, as shown in Figure 1. Risk perception is negatively related to profit. The quantity of collected straw and all of the stakeholders' profits increase with decreasing risk perception. Under the current situation, decreasing the risk coefficient increases the incentive rate for the farmer and the purchase price offered to him (Figure 4e,f).

These results approximate reality. As stated by a power plant manager in an interview, the current profits of the plant and middlemen are US\$950,000 and US\$580,000, respectively (Figure 4b). The manager also said that if the biomass power plant collects biomass strictly within a 30-km radius, the estimated profit that a farmer can earn is US\$360,000. This value is represented with a risk coefficient of 0.08 (Figure 4c). The analyses of the three stakeholders' profits suggest that their risk coefficient is 0.08 . 

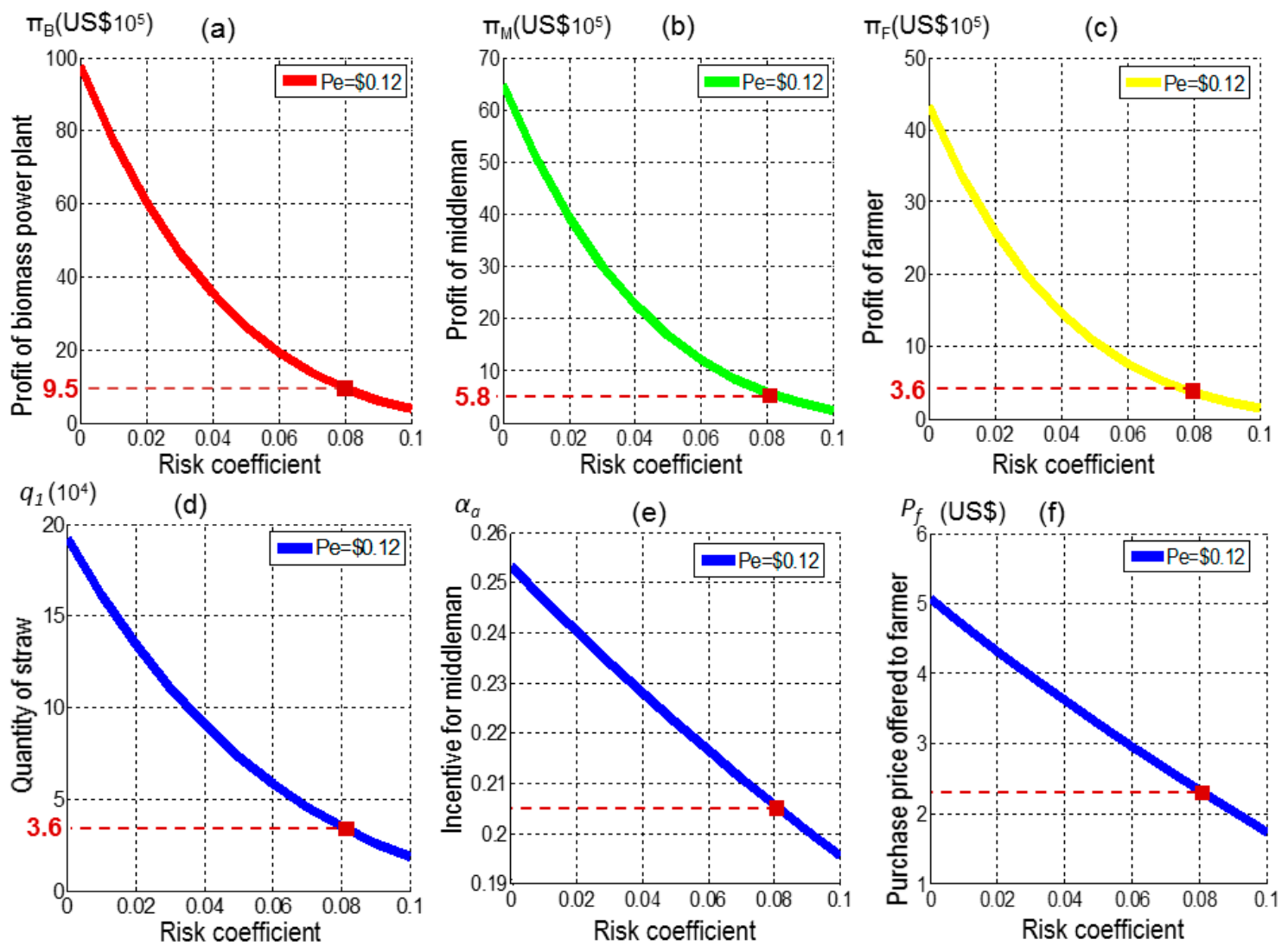

Figure 4. Changes of profits and $\alpha_{a}, p_{f}$, and $q_{1}$ under risk perception in the current incentive situation. (a) Description of profit change of biomass power plant; (b) Description of profit change of middleman;

(c) Description of profit change of farmer; (d) Description of $\alpha_{a}$ change (e) Description of $p_{f}$ change;

(f) Description of $q_{1}$ change.

However, the simulation results for the quantity of collected straw at a risk coefficient of 0.08 is only 36,000 tons, which is one-fifth of the actual total quantity of collected biomass. This finding is attributed primarily to the existence of two kinds of farmers: one unwilling to independently burn and sell straw $\left(\mathrm{F}_{\text {burn }}\right)$ and one who sells straw to middlemen $\left(\mathrm{F}_{\text {sell }}\right)$. We assume that $\mathrm{F}_{\text {burn }}$ expects no profit to be earned from selling straw, whereas $\mathrm{F}_{\text {sell }}$ expects the opposite. That is:

$$
\begin{aligned}
& \prod_{F_{\text {sell }}}=\left\{p_{f}-\left(1+R_{F_{\text {sell }}}\right) \times C\right\} \times Q_{\text {sell }} \cdots>0 \\
& \prod_{F_{\text {burn }}}=\left\{p_{f}-\left(1+R_{F_{\text {burn }}}\right) \times C\right\} \times Q_{\text {burn }} \cdots=0
\end{aligned}
$$

The influence of the existence of $\mathrm{F}_{\text {burn }}$ is analyzed as follows. When farmers are regarded as one entity, the risk coefficient $\left(R_{F}\right)$ is:

$$
R_{F}=\frac{1}{s+b}\left(s R_{F_{\text {sell }}}+b R_{F_{\text {burn }}}\right)
$$

where $s$ and $b$ are the ratios of the quantity of straw possessed by $\mathrm{F}_{\text {sell }}$ and $\mathrm{F}_{\text {burn }}$, respectively.

$$
s+b=1
$$


A farmer's total profit can then be recalculated as follows:

$$
\begin{aligned}
& \prod_{F}=\left\{p_{f}-\left(1+R_{F}\right) \times C\right\} \times Q \\
& =\left\{(s+b) p_{f}-\left[(s+b)+\left(s R_{F_{\text {sell }}}+b R_{F_{\text {burn }}}\right)\right] \times C\right\} \times Q \\
& =\left\{p_{f}-\left(1+R_{F_{\text {sell }}}\right) \times C\right\} \times s Q+\left\{p_{f}-\left(1+R_{\text {burn }}\right) \times C\right\} \times b Q \\
& =\left\{p_{f}-\left(1+R_{F_{\text {sell }}}\right) \times C\right\} \times s Q
\end{aligned}
$$

The result of this equation indicates that even though all farmers have $Q$ tons of straw within a $30-\mathrm{km}$ radius, the actual transaction volume of $s Q$ tons is produced only by $\mathrm{F}_{\text {sell }}$. This model implies that actual transaction volume is proportional to the ratio of straw possessed by $\mathrm{F}_{\text {sell }}$.

The interviewed biomass power plant manager estimates $s$ to be approximately $1 / 2$ of the total proportion. If this estimation is correct, the proposed model still underestimates the collected quantity of straw. Three factors drive this underestimation. First, some farmers who have built a trusting relationship with middlemen ask the latter to collect and transport biomass for free or at very low prices. The biomass collected and transported in this manner is excluded from the modeling in this work. Second, an error may have occurred during modeling given that the model assumptions may not necessarily represent actual conditions. In particular, the risk coefficients of the stakeholders are assumed equal for simplicity in analysis. Such assumption, however, can be debatable. Improving modeling precision necessitates more accurate estimations of the risk coefficient of each stakeholder. Third, the actual quantity of farmers' sold straw to the middleman may not be $1 / 2$ of the total proportion. The inaccurate estimation of farmers' sold straw to the middleman may also cause the underestimation in the model.

The biomass power plant collects biomass from other sources to satisfy demand. The first sources are "free biomass", which consist of leaves and branches scattered in the mountains. The second sources are straw suppliers located outside the $30 \mathrm{~km}$ radius.

The results obtained by the proposed model, in which risk coefficients are introduced, approximate reality and demonstrate the importance of reducing the risk coefficients of all the stakeholders. We recognize that room for improvement in the model exists, but we believe it remains worth using. Analysis to which the risk coefficient $(\mathrm{R})$ is introduced facilitates the understanding of factors that cause inactive biomass collection and the formulation of measures for invigorating this process.

\subsubsection{Scenario 2: Incentive for the Farmer}

By substituting the parameter values into the incentive in the farmer model, we can determine the Nash equilibrium under government incentivization for the farmer as follows:

$$
E_{1}^{* *}=\left(\begin{array}{c}
\alpha_{a}^{* *} \\
p_{f}^{* *} \\
q^{* *}
\end{array}\right)=\left(\begin{array}{c}
\frac{43\left(p_{e}-0.05\right)}{3(1+R)}+\frac{1}{3}(1+R)-\frac{4}{9} \alpha_{g f}(1+R)-\frac{13}{12} \\
\frac{860\left(p_{e}-0.05\right)}{3(1+R)^{2}}-\frac{5}{3(1+R)}-\frac{200}{9} \alpha_{g f}-\frac{40}{3} \\
\frac{1}{12}\left(\frac{860\left(p_{e}-0.05\right)}{(1+R)^{3}}-\frac{5}{(1+R)^{2}}+\frac{160}{3(1+R)} \alpha_{g f}-\frac{40}{(1+R)}\right)^{2}
\end{array}\right)
$$

Repeated simulation indicates that $P_{e}=\mathrm{US} \$ 0.116$ is suitable in this scenario when considering the effects of risk coefficient changes on $\alpha_{a}, p_{f}$, and $q_{1}$ under perceived risk. $P_{e}$ here is, thus, a constant value. The results of changes in $\alpha_{a}, p_{f}$, and $q_{1}$, as well as the changes in the profits of the biomass power plant, middleman, and farmer, are presented in Figure 5. These findings are derived with respect to 
changes in the risk coefficient (from 0 to 0.1 ). The profits of biomass power plant, middleman, and farmer are represented by the following formulae, respectively:

$$
\begin{aligned}
& \prod_{B}=\frac{1}{36(1+R)^{6}}\left[860\left(p_{e}-0.05\right)-40(1+R)^{2}+\frac{160}{3} \cdot \alpha_{g f}(1+R)^{2}-5(1+R)\right]^{3} \\
& \prod_{M}=\frac{1}{54(1+R)^{7}}\left[860\left(p_{e}-0.05\right)-40(1+R)^{2}+\frac{160}{3} \alpha_{g f}(1+R)^{2}-5(1+R)\right]^{3} \\
& \prod_{F}=\frac{1}{108(1+R)^{8}}\left[860\left(p_{e}-0.05\right)-40(1+R)^{2}+\frac{160}{3} \alpha_{g f}(1+R)^{2}-5(1+R)\right]^{3}
\end{aligned}
$$
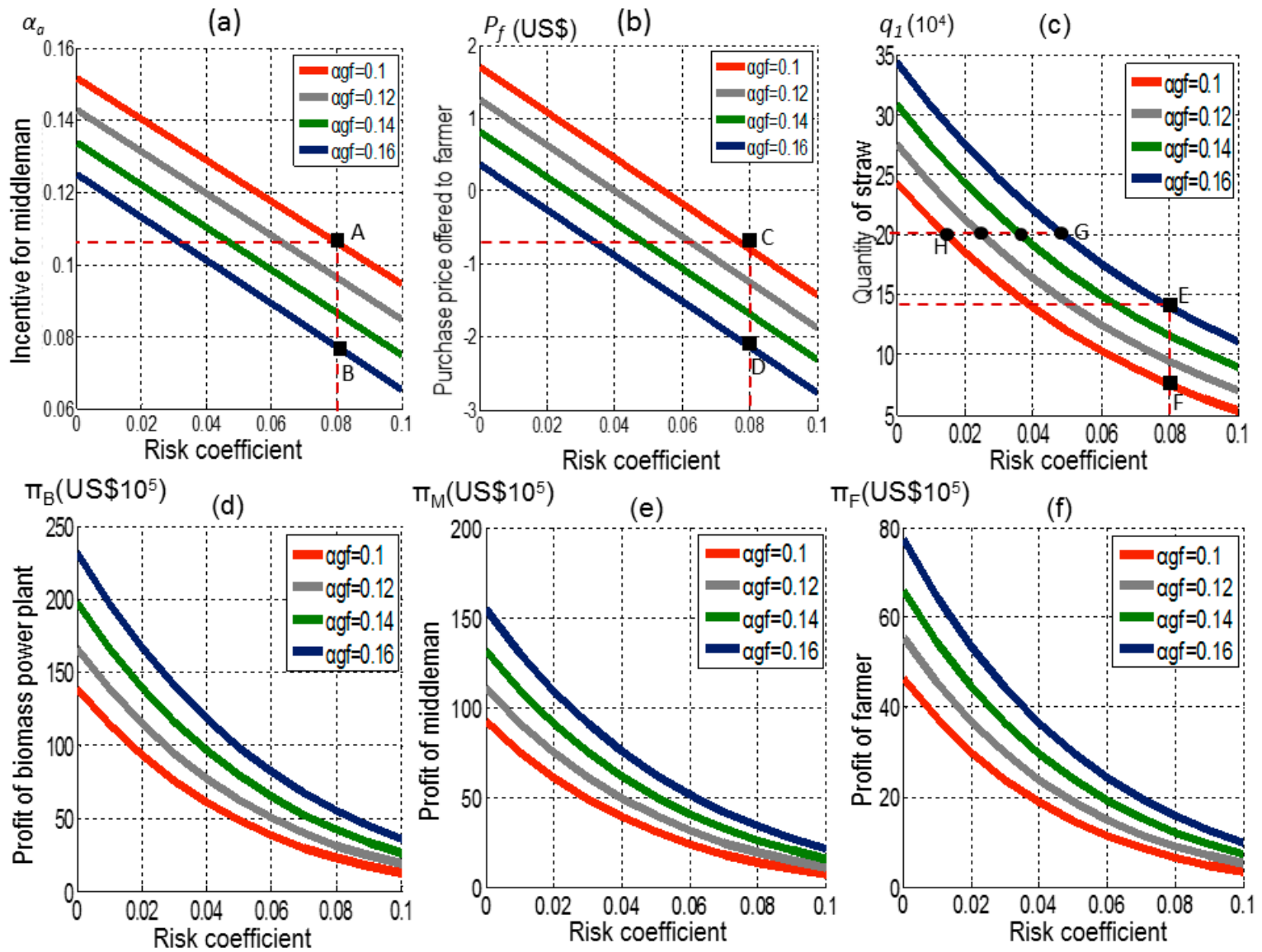

Figure 5. $\alpha_{a}, p_{f}, q_{1}$ and changes of profitsunder risk perception in incentive for the farmer situation. (a) Description of $\alpha_{a}$ change; (b) Description of $p_{f}$ change; (c) Description of $q_{1}$ change; (d) Description of profit change of biomass power plant; (e) Description of profit change of middleman; (f) Description of profit change of farmer.

As expected, the incentive scenario involving the farmer results in significantly lower $\alpha_{a}$ and $p_{f}$ than those derived in the baseline scenario (current situation). With increasing government incentive for the farmer, $\alpha_{g f}, \alpha_{a}$, and $p_{f}$ decrease from A to B and from C to D, respectively (Figure $5 \mathrm{a}, \mathrm{b}$ ). The quantity of straw that the farmer supplies increases from $\mathrm{F}$ to $\mathrm{E}$ as the government incentive increases. Given a certain amount of straw that the biomass power plant demands ( $q_{1}=200,000$ tons), reducing the farmer's risk perception decreases incentives from $\mathrm{G}$ to $\mathrm{H}$ (Figure $5 \mathrm{c}$ ). For changes in the profits earned by the biomass power plant, middleman, and farmer, a rising $\alpha_{g f}$ increases the profits of all the stakeholders, whereas increasing perceived risk decreases such profits (Figure 5e-f). 


\subsubsection{Scenario 3: Incentive for the Middleman}

Further investigating equilibrium through the case study on the incentive for the middleman produces interesting and distinct results. In accordance with the parameters in actual situations, substituting parameter values into the incentive in the middleman model enables us to determine the Nash equilibrium under government incentivization; thus:

$$
E^{* * *}=\left(\begin{array}{c}
\alpha_{a}^{* * *} \\
p_{f}^{* * *} \\
q^{* * *}
\end{array}\right)=\left(\begin{array}{c}
\frac{43\left(p_{e}-0.05\right)}{3(1+R)}+\frac{1+R}{3}-\frac{1}{3} \alpha_{g m}-\frac{13}{12} \\
\frac{860\left(p_{e}-0.05\right)}{3(1+R)^{2}}-\frac{5}{3(1+R)}+\frac{40 \alpha_{g m}}{3(1+R)}-\frac{40}{3} \\
\frac{1}{12}\left(\frac{860\left(p_{e}-0.05\right)}{(1+R)^{3}}-\frac{40}{(1+R)}-\frac{5}{(1+R)^{2}}+\frac{40 \alpha_{g m}}{(1+R)^{2}}\right)^{2}
\end{array}\right)
$$

Substituting $E^{* * *}=\left(\alpha_{a}^{* * *}, p_{f}^{* * *}, q_{1}^{* * *}\right)$ into Equations (2), (4), and (6) yields a plot of the changes in the profits earned by the biomass power plant, middleman, and farmer (Figure 6). Here, $P_{e}$ is a constant value. The profits of biomass power plant, middleman, and farmer are represented by the following formulae, respectively:
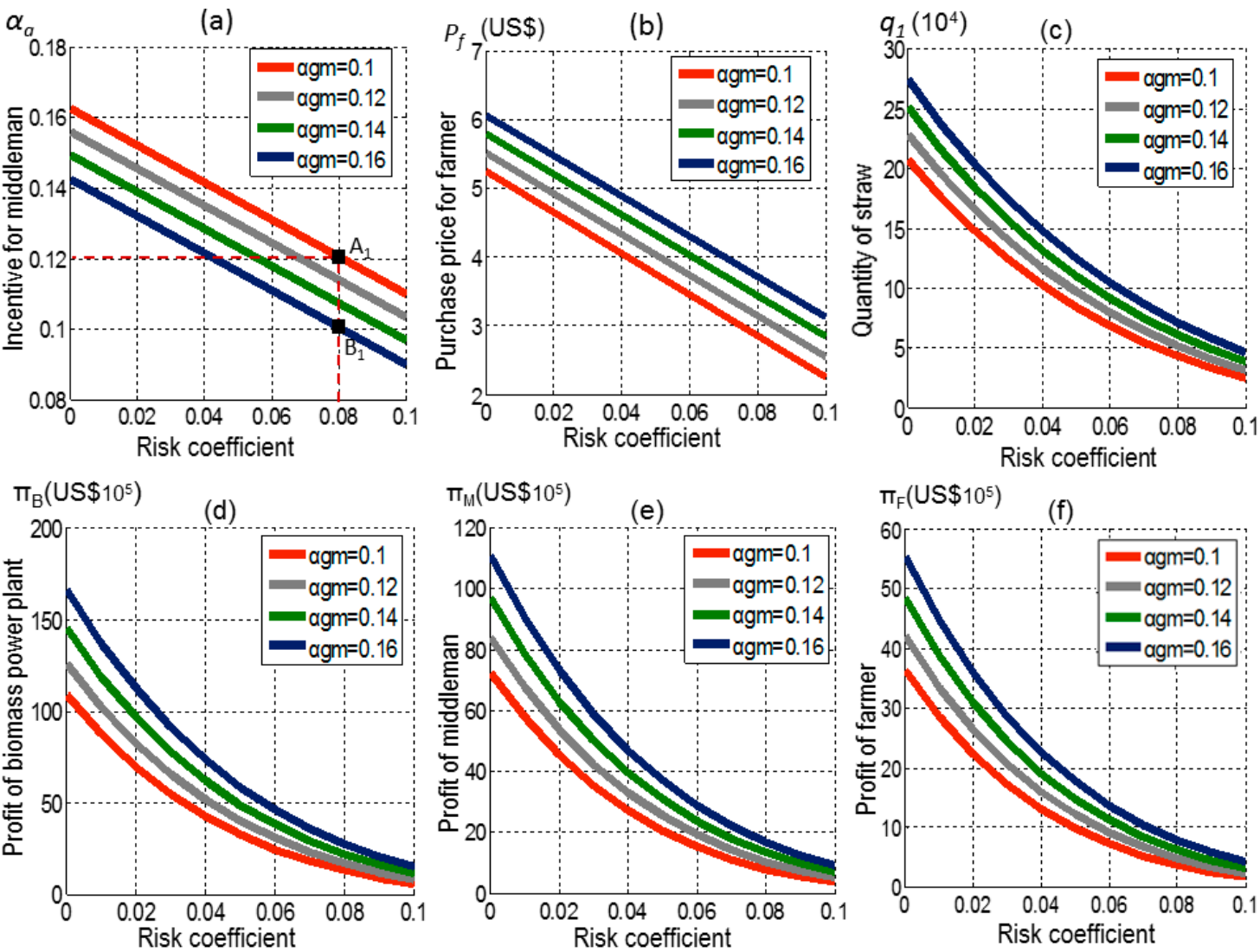

Figure 6. $\alpha_{a}, p_{f}, q_{1}$ and changes of profitsunder risk perception in incentive for the middleman situation. (a) Description of $\alpha_{a}$ change; (b) Description of $p_{f}$ change; (c) Description of $q_{1}$ change; (d) Description of profit change of biomass power plant; (e) Description of profit change of middleman; (f) Description of profit change of farmer.

Similar to the trend in Figure 5a, the incentive from the biomass power plant decreases from $A_{1}$ to $B_{1}$ under increased government incentivization for the middleman. However, the power plant's incentive for the middleman is considerably higher in Figure 6 than in Figure 5a under the same situation (e.g., $R=0.08, \alpha_{g f}=0.16$ ). Moreover, the purchase price offered to the farmer 
$\left(p_{f}\right)$ increases as the government's incentive increases $\left(\alpha_{g m}\right)$. This result differs from that shown in Figure $5 \mathrm{~b}$. The differences highlight the fact that with incentives from the government, middlemen prefer buying straw from farmers at a high price because they want to satisfy demand from biomass power plants (Figure 6b). If the farmer obtains an incentive, he will be inclined to sell straw at a low price (Figure $5 b$ ). Note that the results in Figure $6 b$ are more intensive than those in Figure $5 b$, indicating that the effect of incentives on the middleman is not as obvious as that on the farmer. In terms of the straw quantity demanded by the biomass power plant (i.e., 200,000 tons), in the scenario incentive involving the middleman, satisfying the demand quantity necessitates a risk perception lower than 0.02. Even under the highest incentive $\left(\alpha_{g m}=0.16\right)$, risk perception should still be controlled to around 0.021-an impractical requirement in the short term. The profit trend in Figure 6 is similar to that in Figure 5, but under the same perceived risk, a higher incentive is necessary to reach the same level of profit as that indicated in Figure $5 \mathrm{~d}-\mathrm{f}$. To earn a US $\$ 10$ million profit, for example, the lowest incentive $\left(\alpha_{g f}=0.1\right)$ for the farmer is sufficient under a risk coefficient of 0.02 (Figure $5 \mathrm{~d}$ ). In the middleman scenario, however, the same profit is earned only at a higher incentive $\left(\alpha_{g f}=0.14\right)$ for the middleman (Figure 6d). A particularly surprising result is that, unlike Figure 5e, Figure $6 \mathrm{~d}$ shows that profit decreases remarkably after an incentive is received from the government. At a risk level of 0.02 , the profits earned by the farmer are approximately US\$3.6 and US\$2.2 million under middleman incentives of $0.16\left(\alpha_{g m}=0.16\right)$ and $0.1\left(\alpha_{g m}=0.1\right)$, respectively. Figure $5 \mathrm{f}$ shows that under the same risk level, the farmer can earn a profit of approximately US $\$ 5.3$ million with 0.16 of farmer incentive $\left(\alpha_{g f}=0.16\right)$, and US $\$ 3$ million with 0.10 of farmer incentive $\left(\alpha_{g f}=0.10\right)$. Generally, the results in Figure 6 are more intensive than those in Figure 5. As previously stated, this difference indicates that the incentive for the farmer exerts a strong effect on profit. On the basis of these findings, we draw the following conclusions:

Profit increases with government incentivization for either the middleman or the farmer. The rate of increase depends on the extent of incentives and the perceived risk levels of the three stakeholders.

1. Under a certain perceived risk level, the biomass power plant can obtain its target straw quantity at a farmer incentive that is lower than the middleman incentive. Additionally, the incentive for the farmer exerts a strong effect on increases in the profits of all the stakeholders.

2. The incentive for the farmer produces high profits for the biomass power plant, middleman, and farmer. Although the incentive for the middleman can also increase stakeholder profit to levels higher than that achieved in the current situation, the level of increase is lower than that gained under the farmer scenario.

3. Perceived risk level considerably affects the values of $\alpha_{a}, p_{f}, q_{1}$, and the changes in the profits earned by the three stakeholders. Decreasing perceived risk level can significantly increase crop straw collection and profit.

\subsubsection{Social Welfare Estimation}

The solutions of our models illuminate implications for how perceived risk in the biomass supply chain has affected the profitability of each stakeholder under different subsidy incentive scenarios. Our model results can be used to analyze social welfare, as in the following estimation of social surplus [34]:

$$
\text { Social welfare }=\mathrm{BS}+\mathrm{MS}+\mathrm{FS}+\mathrm{IS}-\mathrm{C}_{\text {incentive }}
$$

where BS, MS, and FS stand for the surpluses of the biomass power plant, middleman, and farmer, respectively (profit of each stakeholder). IS represents the government's incentive surpluses (profit associated with government incentive), and IC is the cost associated with the government's incentives. In this study, the surpluses of the biomass power plant, middleman, and farmer are their net profits. The government's incentive surplus (IS) can be computed by $\left(p_{e}-p_{e}^{\prime}\right) Q_{\text {electricity }}$, where $P_{e}$ is the current price at which the State Grid Corporation of China purchases electricity, and $p_{e}^{\prime}$ is the electricity price after the government decides to subsidize the middleman and farmer. The monetary incentive 
cost $\left(\mathrm{C}_{\text {incentive }}\right)$ can be computed by $\alpha_{g f}\left(\alpha_{g m}\right) \times q_{1} \times p_{m}$. The social welfare for each scenario is shown in Table 2. Note that for the benchmark scenario, four levels of perceived risk are chosen given that the perceived risks of the three stakeholders are considerably high. That social welfare changes with changing levels of perceived risk is an obvious observation. In the incentive scenarios involving the farmer and middleman, however, only the 0.04 and 0.02 levels of perceived risk are used because after the provision of incentives, perceived economic risk is expected to decrease. This study assumes the perceived risk decreases to two alternatives: 0.04 and 0.02 .

Table 2. Results of social welfare in all scenarios (US\$ million/year).

\begin{tabular}{cccccccc}
\hline$\left(\boldsymbol{P}_{\boldsymbol{e}}, \mathbf{R}, \boldsymbol{\alpha}_{\mathrm{gf}} / \boldsymbol{\alpha}_{\mathrm{gm}}\right)$ & Scenario & $\mathbf{B S}$ & $\mathbf{M S}$ & $\mathbf{F S}$ & IS & $\mathbf{C}_{\text {incentive }}$ & Social Welfare \\
\hline$(0.12,0.08)$ & 1 & 0.946 & 0.584 & 0.360 & 0 & 0 & 1.890 \\
$(0.12,0.06)$ & 1 & 1.932 & 1.215 & 0.764 & 0 & 0 & 3.911 \\
$(0.12,0.04)$ & 1 & 3.549 & 2.275 & 1.458 & 0 & 0 & 7.282 \\
$(0.12,0.02)$ & 1 & 6.047 & 3.952 & 2.583 & 0 & 0 & 12.582 \\
$(0.116,0.04,0.1)$ & 2 & 6.018 & 3.915 & 1.883 & 0.8 & 0.793 & 13.409 \\
$(0.116,0.04,0.12)$ & 2 & 7.738 & 4.960 & 2.384 & 0.8 & 0.952 & 16.834 \\
$(0.116,0.04,0.14)$ & 2 & 9.634 & 6.176 & 2.969 & 0.8 & 1.110 & 20.689 \\
$(0.116,0.04,0.16)$ & 2 & 11.818 & 7.576 & 3.642 & 0.8 & 1.269 & 25.105 \\
$(0.116,0.02,0.1)$ & 2 & 9.352 & 6.402 & 3.138 & 0.8 & 0.793 & 20.485 \\
$(0.116,0.02,0.12)$ & 2 & 11.494 & 7.512 & 3.682 & 0.8 & 0.952 & 24.440 \\
$(0.116,0.02,0.14)$ & 2 & 13.940 & 9.111 & 4.466 & 0.8 & 1.110 & 29.427 \\
$(0.116,0.02,0.16)$ & 2 & 16.712 & 10.922 & 5.354 & 0.8 & 1.269 & 35.057 \\
$(0.116,0.04,0.1)$ & 3 & 4.243 & 2.720 & 1.307 & 0.8 & 0.793 & 9.863 \\
$(0.116,0.04,0.12)$ & 3 & 5.172 & 3.315 & 1.594 & 0.8 & 0.952 & 11.833 \\
$(0.116,0.04,0.14)$ & 3 & 6.180 & 3.962 & 1.905 & 0.8 & 1.110 & 13.957 \\
$(0.116,0.04,0.16)$ & 3 & 7.339 & 4.704 & 2.261 & 0.8 & 1.269 & 16.373 \\
$(0.116,0.02,0.1)$ & 3 & 6.950 & 4.542 & 2.227 & 0.8 & 0.793 & 15.312 \\
$(0.116,0.02,0.12)$ & 3 & 8.226 & 5.376 & 2.635 & 0.8 & 0.952 & 17.989 \\
$(0.116,0.02,0.14)$ & 3 & 9.648 & 6.306 & 3.091 & 0.8 & 1.110 & 20.955 \\
$(0.116,0.02,0.16)$ & 3 & 11.226 & 7.337 & 3.597 & 0.8 & 1.269 & 24.229 \\
\hline
\end{tabular}

In all of the cases, the results indicate that incentivization for the middleman and farmer generally increases the net social welfare to a level higher than that achieved in the benchmark case, regardless of perceived risk level. Incentivization for the farmer, in particular, dramatically enhances social welfare. This finding supports our motivation to develop an economically feasible biomass power generation industry. In each scenario, nonetheless, social welfare significantly decreases because of the perceived risk of each stakeholder. On this basis, we can argue that perceived risk substantially affects the biomass market. Furthermore, the fact that incentivization for the farmer generates the highest social welfare is unsurprising. This finding implies that incentivizing farmers is an effective strategy for developing the biomass power generation industry.

\section{Conclusions and Policy Implications}

The biomass power generation industry is anticipated to rapidly expand in the decades to come. Further promoting its development requires investigations of approaches to eliminating obstacles. In line with the current biomass supply situation in China, this study proposed a Stackelberg game approach to modeling incentive scenarios of biomass supply. We focused on optimizing economic incentives for stakeholders in the biomass supply chain and incorporated these into the supply chain design model.

First, we developed a benchmark scenario to identify the current situation: the incentive currently provided by the biomass power plant to the middleman, the price at which the middleman purchases straw from the farmer, and the quantity of straw that the farmer supplies. The three stakeholders' profits were then maximized. Second, the model for farmer incentivization was further investigated. We expect the emergence of a new incentive model to increase farmers' motivation to participate in straw supply activities. All of the stakeholders' profitability levels remarkably increase. To probe into 
the optimized scenario, we also constructed a model for middleman incentivization. Although all of the stakeholders' profits also increase under this model, the incentive results are not as effective as those achieved in the farmer scenario. Note that all of the scenarios are characterized by perceived risk. The numerical results show that perceived risk tremendously affects all of the stakeholders' motivation to participate in straw collection activities. Decreasing perceived risk can be instrumental in increasing the quantity of straw supply and profitability. Finally, social welfare under the three cases were discussed.

In light of policy issues, limited research has been devoted to capital incentives and the operational performance of biomass supply chains [15]. The analysis of incentive scenarios in China's biomass supply chain points to the ineffectiveness of the current incentive scenario in guaranteeing the quantity of straw collection. If the government provides a portion of incentives to farmers, this population would be encouraged to more actively cooperate with biomass power plants in straw collection. The price that farmers charge for collection would also decrease. Incentivizing farmers is expected to generate higher social welfare than that produced by providing incentives to middlemen.

Perceived risk dramatically affects stakeholder profit and social welfare. Mitigating such risk would not only advance the biomass power generation industry but also increase stakeholder profit and social welfare. This study is an initial attempt at designing incentive scenarios under perceived risk for the biomass supply chain and straw collection activities in China. Implementing incentive measures for farmers necessitates the comprehensive application of approaches that are effective in practice. Concrete studies on incentive approaches for farmers should be carried out.

Acknowledgments: This study was funded by Kochi University of Technology, Kochi city, Japan. The authors are grateful to the manager in the biomass power plant, Wang Lifeng and Li Hongjun, the government officers in the field survey area, Wangkui County, China. We are particularly very much thankful to middlemen and farmers who kindly participated the interview.

Author Contributions: Lingling Wang and Tsunemi Watanabe conceived and designed the Model; Lingling Wang performed the experiments; Lingling Wang and Tsunemi Watanabe analyzed the model; Lingling Wang and Tsunemi Watanabe wrote the paper.

Conflicts of Interest: The authors declare no conflict of interest.

\section{Nomenclature}

$C_{1} \quad$ Storage cost borne by the biomass power plant (US $\$ /$ ton)

$C_{t} \quad$ Transportation cost (US $\left.\$ / \mathrm{km} \cdot \mathrm{ton}\right)$

$C_{2} \quad$ Cost of storage in the collection station (US\$/ton)

$C_{q} \quad$ Intermediate variable (US\$/ $\left.\mathrm{t}^{3 / 2}\right)$

$C_{q}\left(q_{2}\right) \quad$ Total cost of crop straw collection (US\$)

$K \quad$ Ratio of the quantity of used crop straw to biomass feedstock

$L \quad$ Distance from the collection station to biomass power plant $(\mathrm{km})$

OC The biomass power plant's operation cost for generated electricity (US\$/MWh)

$p_{a} \quad$ Price that the biomass power plant offers to the middleman (US\$/ton)

$p_{e} \quad$ Electricity purchased price by the State Grid Corporation of China (US $\$ / \mathrm{kwh}$ )

$p_{f} \quad$ Crop straw purchase price charged by the farmer (US $\$ /$ ton)

$p_{m} \quad$ Market price of processed biomass (US\$/ton)

$p_{t} \quad$ Unit cost of biomass transportation (US\$/t)

$q_{1} \quad$ Quantity of crop straw provided by middleman (ton)

$q_{2} \quad$ Quantity of crop straw supplied by the farmer (ton)

$r \quad$ The ratio of conversion from biomass to electricity ( $\mathrm{MWh} / \mathrm{ton}$ )

$R_{B} \quad$ Risk coefficients of the biomass power plant

$R_{M} \quad$ Risk coefficients of the middleman

$R_{F} \quad$ Risk coefficients of the farmer 
$\alpha_{a} \quad$ Coefficient of incentive for middleman

$\alpha_{g f} \quad$ Incentive from the government for farmer

$\alpha_{g m} \quad$ Incentive from the government for middleman

$\alpha_{i} \quad$ Crop straw output in a unit area (ton)

$\beta \quad$ Tortuosity factor to adjust transport distance

\section{References}

1. Yang, J.; Qiu, H.; Huang, J.; Rozelle, S. Fighting global food price rises in the developing world: The response of China and its effect on domestic and world markets. Agric. Econ. 2008, 39, 453-464. [CrossRef]

2. Ma, J.; Sheng, L. National Bureau of Statistics of China. In China's Statistics Yearbook; China Statistical Press: Beijing, China, 2014.

3. Shen, L.; Liu, L.; Yao, Z.; Liu, G.; Lucas, M. Development potentials and policy options of biomass in China. Environ. Manag. 2010, 46, 539-554. [CrossRef] [PubMed]

4. Huang, J.; Yang, J.; Rozelle, S. China's agriculture: Drivers of change and implications for China and the rest of world. Agric. Econ. 2010, 41, 47-55. [CrossRef]

5. Wang, L.; Watanabe, T.; Xu, Z. Monetization of external costs using lifecycle analysis-A comparative case study of coal-fired and biomass power plants in Northeast China. Energies 2015, 8, 1440-1467. [CrossRef]

6. Matsumura, Y.; Minowa, T.; Yamamoto, H. Amount, availability, and potential use of rice straw (agricultural residue) biomass as an energy resource in Japan. Biomass Bioenergy 2005, 29, 347-354. [CrossRef]

7. Narodoslawsky, M.; Niederl-Schmidinger, A.; Halasz, L. Utilising renewable resources economically: New challenges and chances for process development. J. Clean. Prod. 2008, 16, 164-170. [CrossRef]

8. National Development and Reform Committee. Notification on improving feed-in tariff policy of agriculture or forestry residues power generation, NDRC Release No. 1579, 2010. Available online: http:/ /www.fjdpc. gov.cn/Upload/File/2013/2013122795613264.pdf (accessed on 25 February 2016). (In Chinese)

9. Zhang, Q.; Zhou, D.Q.; Zhang, X.Y.; Huang, G.Q. Game-theoretic approach to simultaneous configuration of platform products and supply chains with one manufacturing firm and multiple cooperative suppliers. Int. J. Production Econ. 2010, 124, 121-136. [CrossRef]

10. Wen, W.; Zhang, Q. A design of straw acquisition mode for China's straw power plant based on supply chain coordination. Renew. Energy 2015, 76, 369-374. [CrossRef]

11. Sun, J.; Lin, J.; Qian, Y. Game-theoretic analysis of competitive agri-biomass supply chain. J. Clean. Prod. 2013, 43, 174-181. [CrossRef]

12. Bai, Y.; Ouyang, Y.; Pang, J.-S. Biofuel supply chain design under competitive agricultural land use and feedstock market equilibrium. Energy Econ. 2012, 34, 1623-1633. [CrossRef]

13. Lise, W.; Linderhof, V.; Kuik, O.; Kemfert, C.; Östling, R.; Heinzow, T. A game-theoretic model of the Northwestern European electricity market-market power and the environment. Energy Policy 2006, 34, 2123-2136. [CrossRef]

14. Nasiri, F.; Zaccour, G. An exploratory game-theoretic analysis of biomass electricity generation supply chain. Energy Policy 2009, 37, 4514-4522. [CrossRef]

15. Esmaeili, M.; Aryanezhad, M.B.; Zeephongsekul, P. A game theory approach in seller-buyer supply chain. Eur. J. Oper. Res. 2009, 195, 442-448. [CrossRef]

16. Leng, M.M.; Zhu, A. Side-payment contracts in two-person nonzero-sum supply chain games: Review, discussion and applications. Eur. J. Oper. Res 2009, 196, 600-618. [CrossRef]

17. Talat, S.G.; Suvrajeet, S. An analysis of capacity and price trajectories for the Ontario electricity market using dynamic Nash equilibrium under uncertainty. Energy Econ. 2008, 30, 173-191.

18. Yue, J.F.; Austin, J.; Wang, M.C.; Huang, Z.M. Coordination of cooperative advertising in a two-level supply chain when manufacturer offers discount. Eur. J. Oper. Res. 2006, 168, 65-85. [CrossRef]

19. Choi, C.S. Price competition in a channel structure with a common retailer. Mark. Sci. 1991, 10, 110-129. [CrossRef]

20. Lee, E.; Staelin, R. Vertical Strategic Interaction: Implications for Channel Pricing Strategy. Mark. Sci. 1997, 16, 185-207. [CrossRef]

21. Raju, J.; Zhang, Z.J. Channel coordination in the presence of a dominant retailer. Mark. Sci. 2005, 24, 254-262. [CrossRef] 
22. Benjamin, C.; Houee-Bigot, M. Measuring competition between non-food and food demand on world grain markets: Is biofuel production compatible with pressure for food production? In Proceedings of the American Agricultural Economics Association Annual Meeting 2007, Portland, OR, USA, 29 July-1 August 2007.

23. Sun, J.; Chen, J.; Xi, Y.; Hou, J. Mapping the cost risk of agricultural residue supply for energy application in rural China. J. Clean. Prod. 2011, 19, 121-128. [CrossRef]

24. Tsai, C.H.; Zhu, D.S.; Ho, C.T.; Wu, B.; Desheng, D. The effect of reducing risk and improving personal motivation on the adoption of knowledge repository system. Technol. Forecast. Soc. Chang. 2010, 77, 840-856. [CrossRef]

25. Wu, D.; Olson, D.L. Introduction to special section on "risk and technology". Technol. Forecast. Soc. Chang 2010, 77, 837-839. [CrossRef]

26. Engelmann, J.B.; Tamir, D. Individual differences in risk preference predict neural responses during financial decision-making. Brain Res. 2009, 1290, 28-51. [CrossRef] [PubMed]

27. Fraedrich, J.P.; Ferrell, O.C. The impact of perceived risk and moral philosophy type on ethical decision making in business organizations. J. Bus. Res. 1992, 24, 283-295. [CrossRef]

28. Liao, C.; Lin, H.N.; Liu, Y.P. Predicting the use of pirated software: A contingency model integrating perceived risk with the theory of planned behavior. J. Bus. Ethics 2010, 91, 237-252. [CrossRef]

29. Mitchell, V.W. Consumer perceived risk: Conceptualizations and models. Eur. J. Market. 1999, 33, $163-195$. [CrossRef]

30. Jiang, D.; Zhuang, D.F.; Fu, J.Y.; Huang, Y.H.; Wen, K.G. Bioenergy potential from crop residues in China: Availability and distribution. Renew. Sustain. Energy 2012, 16, 1377-1382. [CrossRef]

31. Xing, A.; Liu, G.; Wang, Y.; Wei, F.; Jin, Y. Economic, energy and environment analysis on biomass collection process. Chin. J. Process Eng. 2008, 8, 306-313. (In Chinese)

32. Roos, A.; Rakos, C. The limits of modelling. Experiences with bioenergy in practice-could models have predicted this outcome? Biomass Bioenergy 2000, 18, 331-340. [CrossRef]

33. Wang, X.Y.; Yang, L.; Steinberger, Y.; Liu, Z.X.; Liao, S.H.; Xie, G.H. 2013. Field crop residue estimate and availability for biofuel production in China. Renew. Sustain. Energy 2013, 27, 864-875. [CrossRef]

34. Sadeghi, H.; Abdollahi, A.; Rashidinejad, M. Evaluating the impact of FIT financial burden on social welfare in renewable expansion planning. Renew. Energy 2015, 75, 199-209. [CrossRef]

(C) 2016 by the authors; licensee MDPI, Basel, Switzerland. This article is an open access article distributed under the terms and conditions of the Creative Commons Attribution (CC-BY) license (http://creativecommons.org/licenses/by/4.0/). 